\title{
Effectiveness Study on the Integration of Information Technology and Kindergarten Teaching
}

\author{
Shaohua Nie \\ Linyi University, Linyi, Shandong Province, China
}

Keywords: Information technology; kindergarten teaching; integrate; effectiveness.

\begin{abstract}
The development of information technology has promoted the reform of kindergarten teaching. The purpose of this paper is to explore how to create an ideal learning environment for young children in modern information technology environment, to change children's traditional and simple ways of learning, and to form the ideal way of learning for young children. Under the guidance of advanced educational philosophy, we can construct "experiential, exploratory and interactive" teaching effectively by means of information technology.
\end{abstract}

\section{The Present Situation of Kindergarten Teaching in Current Information Technology Environment}

Children are excited and lively under current information technology teaching environment, while their learning is passive.

The advantages of multimedia teaching show on the inspiration of children's interest and creation of the environment. Vivid picture, bright colors and realistic animation, presented by multimedia, can create a dynamic learning situation, which can specify abstract things, inspire children's learning interest and motivation and attract children's attention. In information technology teaching environment, children will be particularly excited and lively due to interest and freshness presented by multimedia.

In educational activities, children should be in the dominant position. One of the original intentions of multimedia education activities is to embody the dominant role of children, which isn't effectively reflected now. At present, children's lively is not children's subjectivity, just watch teachers' operation passively.

In current information technology teaching environment, teachers and children are lack of interaction, ignoring the organic unity between them.

Kindergarten teaching is the interaction between teachers and young children. Through interaction, children get the rules of communication, experience, skills, awareness, emotions, attitudes, even personality characteristics. However, under current information technology teaching, children do not have opportunities to operate multimedia personally, and then cannot feel the situation taught by teachers. Teachers and young children also lack necessary interaction; both pay less attention to each other's body language, and are in lack of exchange of true feelings.

Kindergarten teaching is the dynamic interaction process among teachers, children and environment, which teacher and children can play their own subjectivity. The design of educational activities should take into account the children's interest and characteristics, and take the initiative of mobilizing children as the starting point. The activities should be carried out to take care of each child, to ensure the participation of all children, to provide the expression, display and creation space, conditions and opportunities for each child under the circumstance of respect of each child's personality. This kind of teaching is not a true embodiment of effective unity between teachers and children, bustling appearance cover the relationship truth with the help of multimedia aids.

In current information technology environment, teaching is functional single, and children are lack of inquiry about learning 
Many kindergarten teachers are just in superficial understanding of multimedia, did not really realize the role of multimedia playing in teaching. Multimedia is the a whole form collected graphics, text, sound, images, animation, video and other information form, while some teachers only use the image function to just display pictures to watch. Of course, it did not play the desired effect to children.

Activity is the child's nature, is the life of young children. However, the nature of children's "activities" is not an external "specific activity", not an external form, but children's internal mental activity - active thinking, imagination, positive interest, strong motivation, high emotions , strong curiosity, active attitude, creative needs and so on. But now, we noticed that children show interest to superficial form of course, including color and action; teacher's guidance is often difficult to lead children into exploration of process of designed question.

\section{Integration of Information Technology and Kindergarten Teaching}

The Principles of Effective Integration of Information Technology and Kindergarten Teaching. Firmly grasp the goal direction. With the help of information technology, classroom teaching should always start form teaching objectives, instead of deviating from teaching direction with means of multimedia. First of all, teachers should choose the appropriate textbook content with purpose and plan. Teaching content is the core of teaching, while audio-visual media is only a auxiliary teaching form. Teachers should deal with the relationship between content and form, that is, content decide form, form services content. Second, teachers should guide children's learning direction and learning ideas systematically. Multimedia form-color, image, animation and others will attract young children's attention and children are also easy to distract their attention, which requires teachers guide children's thinking and attention to focus on learning content flexibly, timely and effectively.

Closely centre on the subjectivity of young children. Playing children's subjectivity is the core of teaching objectives, the ultimate goal and effect of classroom teaching should be around playing children's subjectivity. Children's subjectivity mainly reflects on activity, exploratory and creative aspects. Preschoolers' thinking, imagination are associated with their movements and activities, it can be said that "no activity, no thinking", and the best way to develop a child's mind is to let it move. "Learning by doing" is indeed the most basic principle of children's learning and development. Therefore, by means of information technology, teachers should mobilize children's learning interest, encourage them to actively participate, fully express, personally operate.

Fully embody the interaction between teachers and children. Teaching in information technology environment must reflect interaction and cooperation between teachers and children. With the help of information technology, teachers should combine contents of courseware and their own content to closely in the process of organizing teaching activities. They should communicate feelings with young children anytime and anywhere to complete interaction between each other, on the basis of fully arouse children's learning enthusiasm and interest, , if necessary, give children opportunity to operate multimedia to strengthen feelings. Let children participate in contents of multimedia by usage of multimedia prompts to complete autonomous learning, then children can be truly as the main body in the teaching activities.

Dig the versatility of information technology. The advantage of multimedia-assisted teaching is obvious, this whole new form, in one set of pictures, text, sound and image, is lively and welcomed by the majority of young children and teachers. Teachers should have a correct understanding of multimedia's various functions while using this new form, instead of simply using just for freshness. Children don't become interested in just seen short film, listened to the story, lacking interaction when necessary. Kindergarten teachers should be good at thinking to make better usage of multimedia to achieve the ultimate goal of promoting the physical and mental development of children.

The Learning Ways for Children in Information Technology. Teaching in information technology context makes class more wonderful, vivid, and more attractive compared with traditional classroom teaching. However, the essence and pursuit of classroom teaching is still that children are the main body of learning, that is to say, the ultimate goal of teaching leads to children's learning and 
development. Therefore, teaching in information technology context needs guide children's autonomous, inquiry and creative learning.

Autonomous learning. The integration of modern educational information technology and kindergarten curriculum is not only using information technology as a supplementary or auxiliary tool, but rather emphasizing information technology as a cognitive and emotional incentive tool to promote children's independent learning. Learning environment, supplied by information technology, are self-explorative, multi-interactive, cooperative learning and resource sharing, which can fully mobilize children's learning initiative and enthusiasm to reflect children's dominant role in learning. Modern information technology, combined map, text, sound and image as one "diversity, novelty, intuitive, flexible" set, which enables that static graphic can speech, complex content becomes simple, abstract thinking become more accessible, usage of knowledge become more apparent. With these above advantages and characteristics, children can learn to obtain, use, synthesis and create information, then form learning habits, learning ability, master learning methods, learn to learn independently, self-learning in information society environment.

Inquiry learning. The inquiry learning in information technology context refers to the activity of children in the classroom or under the guidance of teachers to get the answer, which is derived from the content of multimedia and so on. Compared to narrow, closed, monotonous and traditional classroom, classroom teaching under information technology context is more interesting, more able to meet children's' curiosity and stimulate exploration of psychology. Kindergarten teaching under information technology context should fully reflect the characteristics of encourage children continue to explore and ask, such as multimedia teaching-change the static wall charts to operational dynamic picture, change the teacher's single preaching to vivid voice and sound stimulus, change complex problem to simple and concrete issues, which can lead children to listen, look, focus and calculate carefully, then to unconsciously state of inquiry.

Creative learning. Kindergarten teaching under information technology context of can not only stimulate children's interest in learning, lead them explore actively, but also guide children to achieve a higher level of learning, that is creative learning. Modern educational information technology can break through the limitations of time and space, through feelings of sound and impact of image to provide context to create an intuitive image. In the process, children can generate novel ideas, unique perspective and fantastic thinking; this approach can effectively promote the development of children's thinking, then broaden the way to solve problem. Children can enhance innovative thinking and unique ability to solve the problem through observation, imagination, hands-on operation, positive thinking, and exploration from different angles.

Classroom Teaching in Information Technology Environment. Exploratory teaching. The modernity, flexibility, efficiency, high capacity of fun and knowledge of information technology create and create an attractive teaching scene for children. Bright and vivid images, pleasant sounds, static and dynamic combined images and intelligent inspiration and guidance enable children to always maintain intriguing study condition with curiosity and desire to explore unknown world. In this process, children's psychological factors such as sensation, perception, memory, mind, emotion, can maintain a good state of excitement, which satisfies with children's cognitive psychology, and promote the development of children's thinking ability. In addition, modern information technology teaching can provide a large number of modern scientific and technological knowledge, broaden children's knowledge constantly, lead children to think and explore actively, thereby develop their memory, observation, imagination, thinking and other intellectual factors.

Experiential teaching. The one set multimedia learning situation, created by modern information education technology, attract children's curiosity greatly through form like graphic flashing, discoloration, animation and so on. During teaching process, let children participate and manipulate the multimedia personally, with the changes on the screen by their own hands, each child can feel the fun brought by multimedia teaching, inspired them to speak, think and operate actively, which is beneficial to reflect the connection of old and new experience, to improve children's thinking links, then to assimilate and adapt knowledge. That is learning by doing. Let children to feel, find, 
experience, and create personally, then find fun, get confidence, be successful, be educated, which would improve teaching effect and quality greatly.

Interactive teaching. The wisdom of education should be reflected in emotional interaction in educational activities. Integration and interaction is the two most prominent features of multimedia, and teachers should pay attention to language and emotional exchanges with children when using multimedia teaching methods. Teachers should take the initiative to approach children's inner world, so that children can realize much more fun of learning. Due to age, young children will show a strong curiosity to any new things, so does multimedia with its illustrations, audio and video combined characteristics. In the process of teaching, teachers can create an interactive problem situation, in which teachers and students work together to solve same problem through positive interactions while teachers play an empirical role in guiding the overall direction.

\section{References}

[1] Nan Zhao. Media-assisted kindergarten teaching present situation and countermeasures [D]. Changchun: Northeast Normal University, 2011.

[2] Sumin Guo. Technology and kindergarten mathematics education integration and case study [D]. Changchun: Northeast Normal University, 2011.

[3] Liang Chang, Bin Zeng. Pre-school education information research [J] .School of Pre-school Teachers, 2015, (1).

[4] Yuhong Wu. Using a variety of information technology to carry out environmental education [J]. Science Volkswagen (Science Education), 2016, (6). 